\title{
Hysteresis in the Active Oxidation of SiC
}

\author{
N. S. Jacobson ${ }^{\mathrm{a}}$, B. J. Harder ${ }^{\mathrm{a}}$, and D. L. Myers ${ }^{\mathrm{b}}$ \\ ${ }^{a}$ NASA Glenn Research Center, Cleveland, OH 44135 USA \\ b Department of Chemistry, East Central University, Ada, OK 74820 USA
}

$\mathrm{Si}$ and $\mathrm{SiC}$ show both passive oxidation behavior where a protective film of $\mathrm{SiO}_{2}$ forms and active oxidation behavior where a volatile suboxide $\mathrm{SiO}(\mathrm{g})$ forms. The active-to-passive and passive-to-active oxidation transitions are explored for both $\mathrm{Si}$ and $\mathrm{SiC}$. Si shows a dramatic difference between the $\mathrm{P}\left(\mathrm{O}_{2}\right)$ for the two transitions of $\sim 10^{-4}$ bar. The active-to-passive transition is controlled by the condition for $\mathrm{SiO}_{2} / \mathrm{Si}$ equilibrium and the passive-to-active transition is controlled by the decomposition of $\mathrm{SiO}_{2}$. In the case of $\mathrm{SiC}$, the $\mathrm{P}\left(\mathrm{O}_{2}\right)$ for these transitions are much closer. The active-to-passive transition appears to be controlled by the condition for $\mathrm{SiO}_{2} / \mathrm{SiC}$ equilibrium. The passive-to-active transition appears to be controlled by the interfacial reaction of $\mathrm{SiC}$ and $\mathrm{SiO}_{2}$ and subsequent generation of gases at the interface which leads to scale breakdown.

\section{Introduction}

It is well-known that $\mathrm{SiC}$ exhibits two forms of oxidation: Passive oxidation forms a protective $\mathrm{SiO}_{2}$ film on the surface according to:

$$
\mathrm{SiC}(\mathrm{s})+3 / 2 \mathrm{O}_{2}(\mathrm{~g})=\mathrm{SiO}_{2}(\mathrm{~s})+\mathrm{CO}(\mathrm{g})
$$

At higher temperatures and lower oxygen potentials, there is a transition to active oxidation. Active oxidation leads to a volatile sub-oxide according to:

$$
\mathrm{SiC}(\mathrm{s})+\mathrm{O}_{2}(\mathrm{~g})=\mathrm{SiO}(\mathrm{g})+\mathrm{CO}(\mathrm{g})
$$

The critical issues to understand in this area are the transitions between passive and active oxidation and the rates of active oxidation. These issues are critical in the design of SiCbased ceramic and composite hypersonic leading edges, which would be exposed to high temperatures and high temperatures.

These processes can best be understood by looking to the literature on pure Si oxidation. Wagner (1) has shown that the active-to-passive and passive-to-active transitions, which occur as oxygen potential is changed, exhibit a hysteresis shown schematically in Fig. 1. The active-to-passive transition is governed by the condition for equilibrium between $\mathrm{Si}$ and $\mathrm{SiO}_{2}$ :

$$
\mathrm{Si}(\mathrm{c})+\mathrm{SiO}_{2}(\mathrm{~s})=2 \mathrm{SiO}(\mathrm{g})
$$


As oxygen pressure is gradually increased, more $\mathrm{SiO}(\mathrm{g})$ forms, until finally there is sufficient $\mathrm{SiO}(\mathrm{g})$ to satisfy the above equilibrium. Wagner includes the effect of the boundary layer and derives the expression for the transition as:

$$
P_{\mathrm{O}_{2}}^{\text {active-to-passive }}=\frac{1}{2}\left(\frac{D_{\text {SiO }}}{D_{\mathrm{O}_{2}}}\right)^{1 / 2} P_{\mathrm{SiO}}^{e q}
$$

Here $D_{i}$ is the diffusivity of species $i$ in the inert gas diluent ( $\mathrm{Ar}$ in this case) and $P_{S i O}^{e q}$ is the equilibrium pressure of $\mathrm{SiO}(\mathrm{g})$ calculated from reaction [3]. The passive-to-active transition is due to the decomposition of $\mathrm{SiO}_{2}(\mathrm{~s})$ :

$$
\mathrm{SiO}_{2}(\mathrm{~s})=\mathrm{SiO}(\mathrm{g})+1 / 2 \mathrm{O}_{2}(\mathrm{~g})
$$

Based on these two mechanisms, the difference in oxygen partial pressure for the activeto-passive transition and the passive-to-active transition is about four orders of magnitude (1).

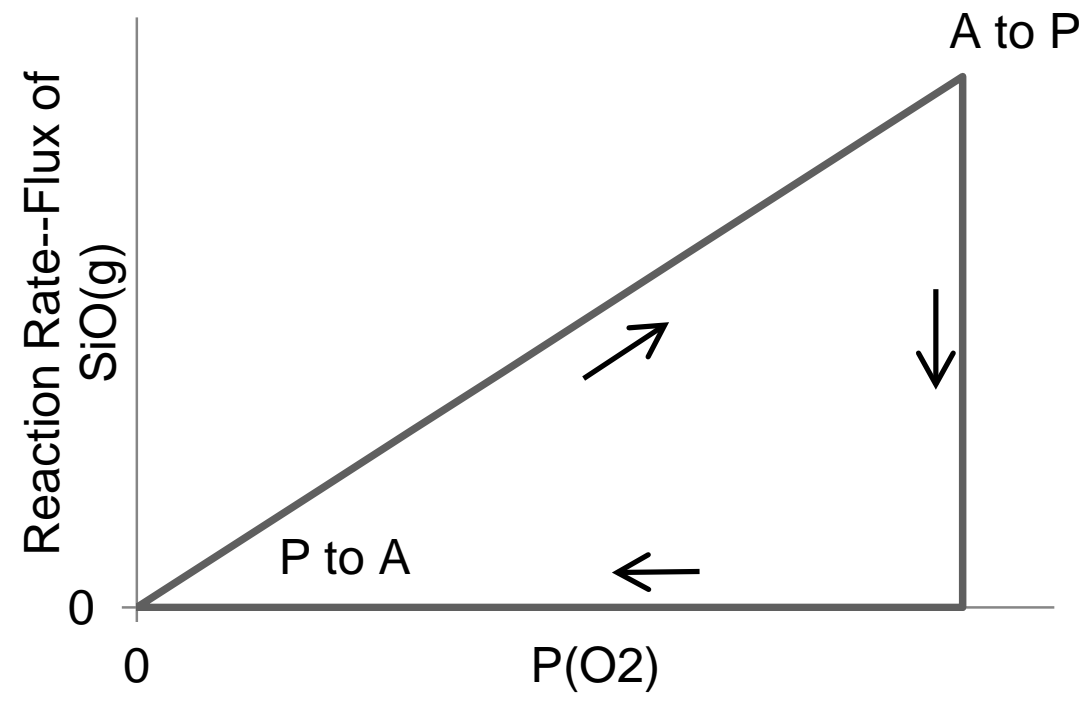

Fig.1. Schematic diagram showing the hysteresis in the active (A)/passive (P) oxidation of Si (adapted from Wagner (1)).

Previous investigations of active oxidation have not given adequate attention to the hysteresis between active-to-passive and passive-to-active transitions (2). Understanding this difference is important to predict the oxidation behavior of $\mathrm{SiC}$ based ceramics and composites in hypersonic re-entry conditions. Most of the literature is on the active-to-passive transition, whereas in application it is the passive-to-active transition that is most important. In this study we first examine the transitions for pure Si and then for SiC. This study establishes that the active-to-passive and the passive-toactive transitions occur at different oxygen potentials and caused by different mechanisms for both $\mathrm{Si}$ and SiC.

\section{Experimental}


Four types of starting materials were used-semiconductor grade $\mathrm{Si}$, Si-rich $\mathrm{SiC}$ (Saint Gobain, Niagara Falls, NY), stoichiometric chemically vapor deposited SiC (Morton Technical Ceramics, Hudson, NH), and C-rich sintered SiC (Hexoloy, Saint Gobain, Niagara Falls, NY). Coupons approximately 1 x 1 x $0.1 \mathrm{~cm}$ were used for all materials.

Furnace exposures were conducted in a thermogravimetric apparatus. The sample was suspended from a recording microbalance (Cahn R-1000, Cerritos, CA) in a vertical

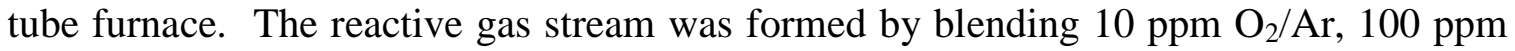
$\mathrm{O}_{2} / \mathrm{Ar}, 1000 \mathrm{ppm} \mathrm{O}_{2} / \mathrm{Ar}$, and $5 \% \mathrm{O}_{2} / \mathrm{Ar}$ in a glass bead mixer. Oxygen potential was measured with a zirconia oxygen sensor in the gas line. Transitions were measured by changing the oxygen potential gradually and observing the resultant changes in the weight change kinetics.

After a run, samples were characterized with x-ray diffraction (XRD) and field emission scanning electron microscopy (FE-SEM). The FE-SEM could be operated at low accelerating voltages so that a conductive coating of the samples was not necessary.

\section{Results and Discussion}

\section{$\underline{\text { Active-to-Passive and Passive-to-Active Transitions for } \mathrm{Si}}$}

Experimental results which should the active-to-passive transition for $\mathrm{Si}$ are shown in Fig. 2. This is a plot of plot of weight change vs time, with the oxygen potential decreased at regular intervals. Note the transition occurs with two types of passive oxidation, as observed by Hinze and Graham (3). Stage I is a rapid, nonprotective formation of $\mathrm{SiO}_{2}$, and Stage II is a protective formation of $\mathrm{SiO}_{2}$. The morphology of Stage I oxidation is shown in Fig. 3(a) as rods of $\mathrm{SiO}_{2}$. The mechanism of formation of these rods is shown in Fig. 3(b) and is a result of an oxygen gradient, with oxygen potential increasing away from the Si surface. This observation is important and these rods of $\mathrm{SiO}_{2}$ are an indicator of $\mathrm{SiO}(\mathrm{g})$ formation at the sample surface. 


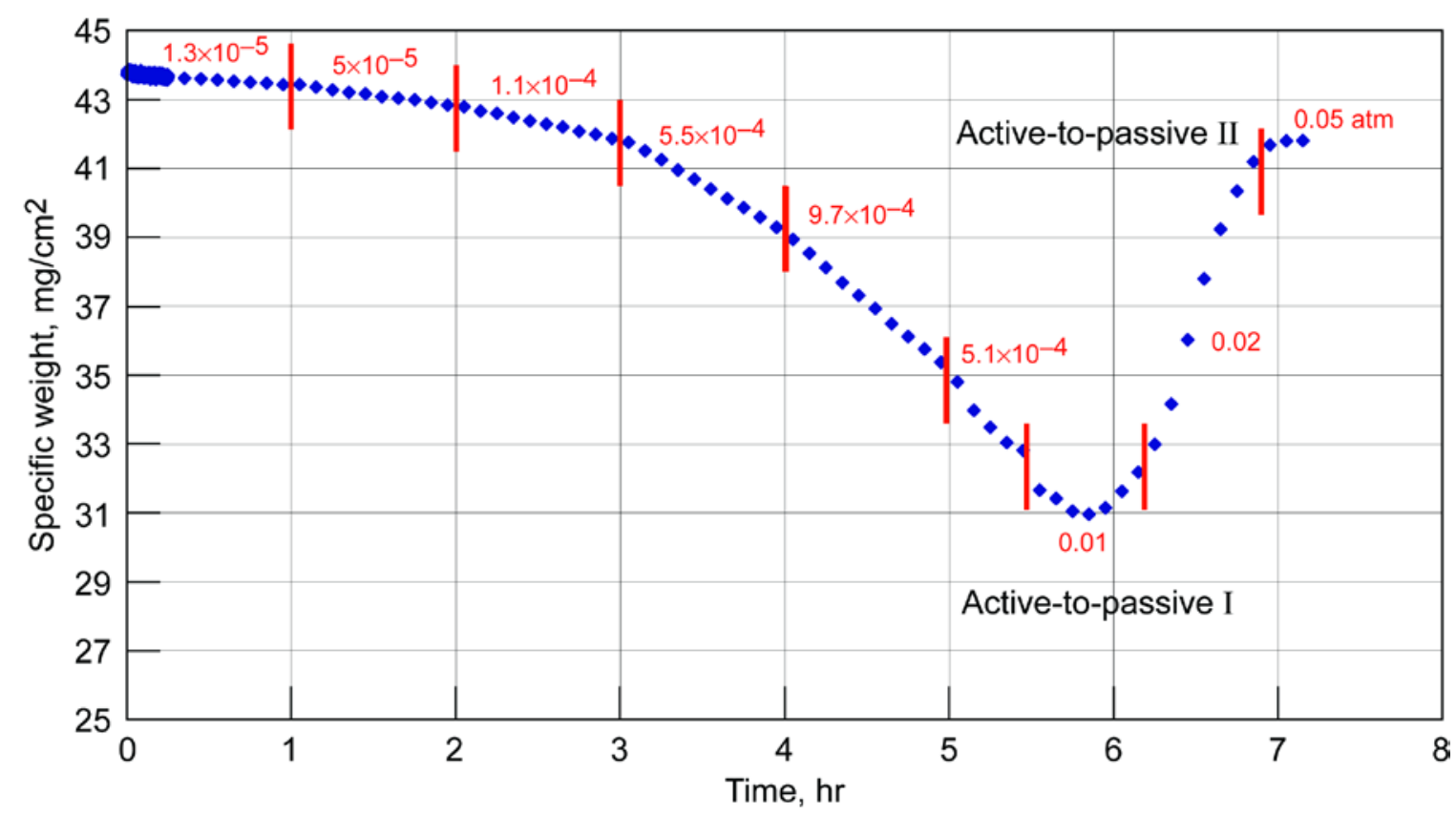

Fig. 2. Weight change vs time at $1310^{\circ} \mathrm{C}$ for pure $\mathrm{Si}$, as oxygen potential is increased at regular intervals. Note the labels in red are the oxygen potentials.

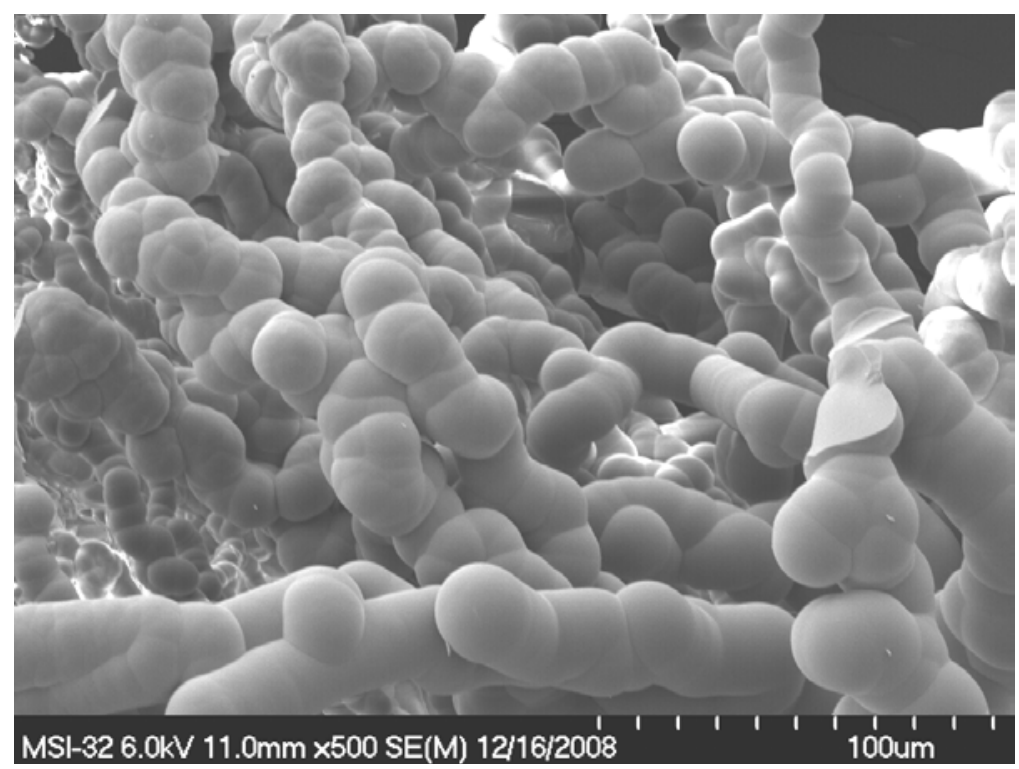

Fig. 3(a) Surface morphology after Stage I oxidation. 

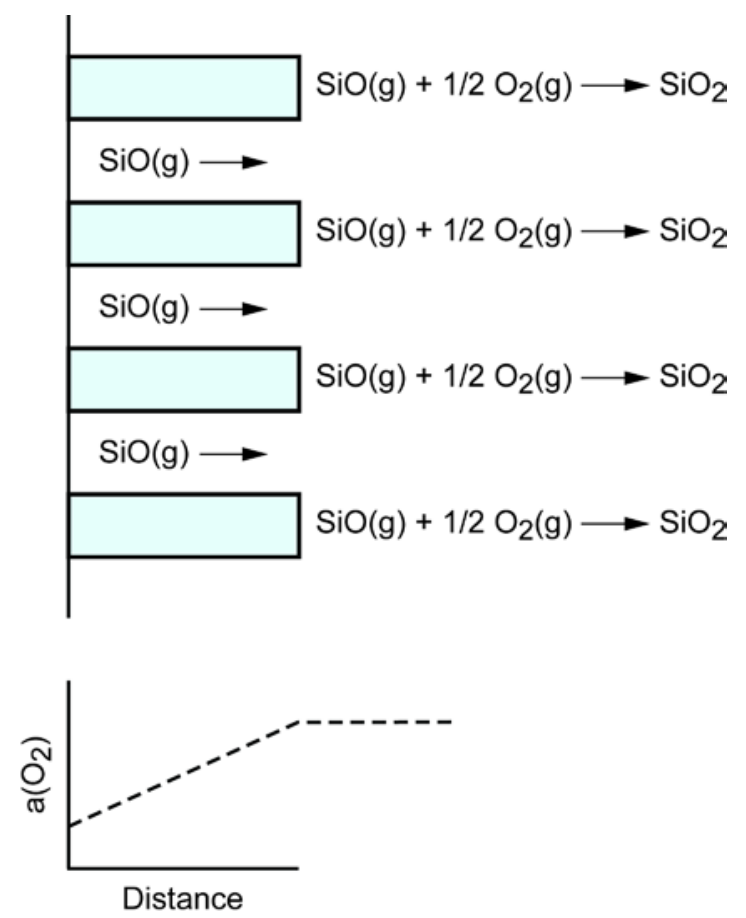

Fig. 3(b). Mechanism for the formation of $\mathrm{SiO}_{2}$ rods. Si or $\mathrm{SiC}$ substrate is on the left.

Further experiments were done to try to identify the passive-to-active transition in $\mathrm{Si}$ (2). However, it was not possible to reach a low enough $\mathrm{P}\left(\mathrm{O}_{2}\right)$ in our system $(<1 \mathrm{x}$ $\left.10^{-5} \mathrm{~atm}\right)$ to trigger the transition to active oxidation. This indicates that the difference between the $\mathrm{P}\left(\mathrm{O}_{2}\right)$ for active-to-passive and passive-to-active was many orders of magnitude, as predicted by Wagner (1).

\section{Active-to-Passive Transitions for SiC}

Figs. 4 and 5 show the experimental results for active-to-passive transitions for $\mathrm{SiC}$ with excess Si and for stoichiometric SiC, respectively. Note the sample with excess Si exhibits the two types of passive oxidation, as observed with pure Si (Fig. 2) and the stoichiometric $\mathrm{SiC}$ sample only exhibits the formation of the protective $\mathrm{SiO}_{2}$ scale. 


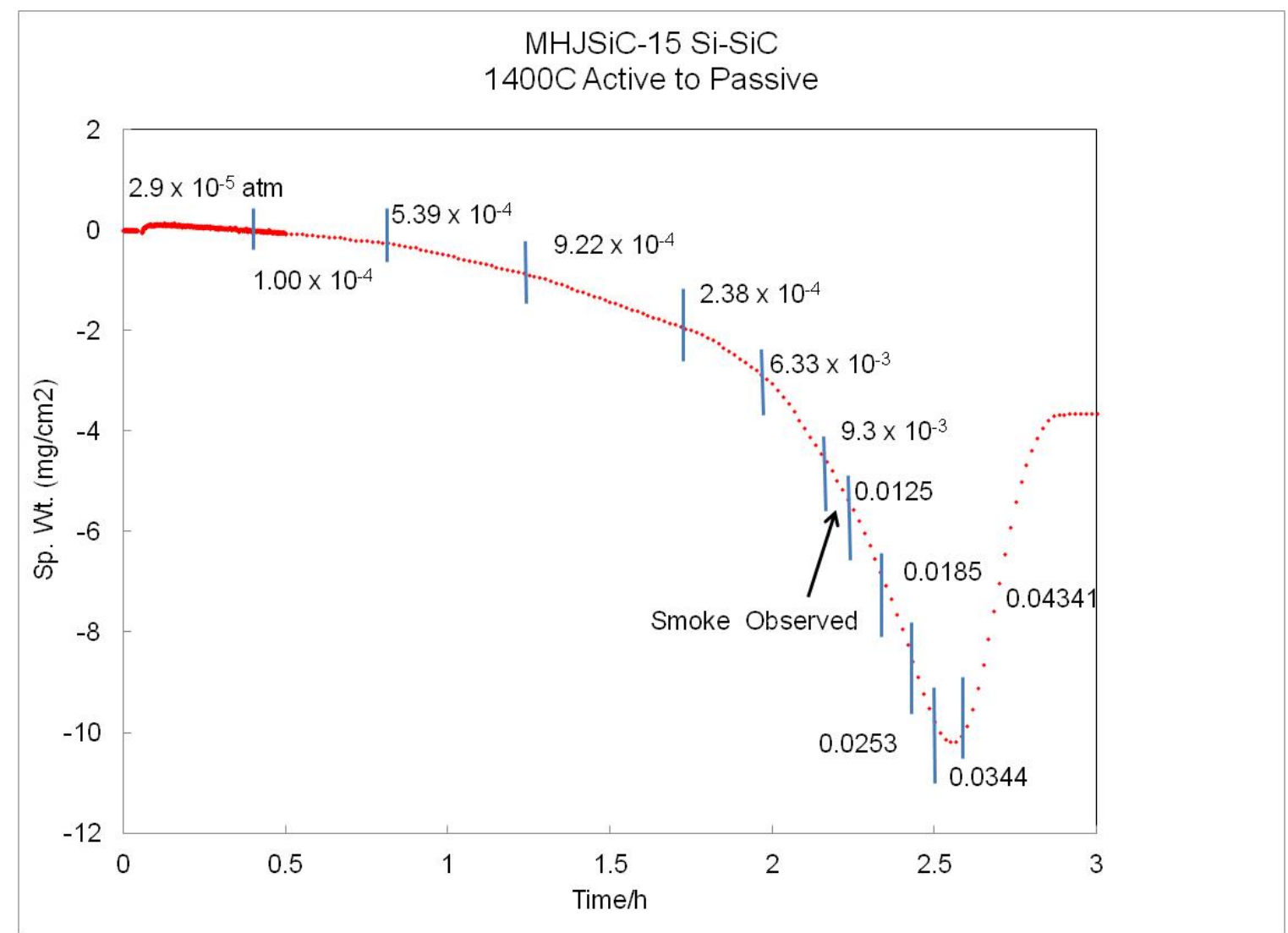

Fig. 4 Active-to-passive transition for $\mathrm{SiC}$ with excess $\mathrm{Si}$ at $1400^{\circ} \mathrm{C}$.

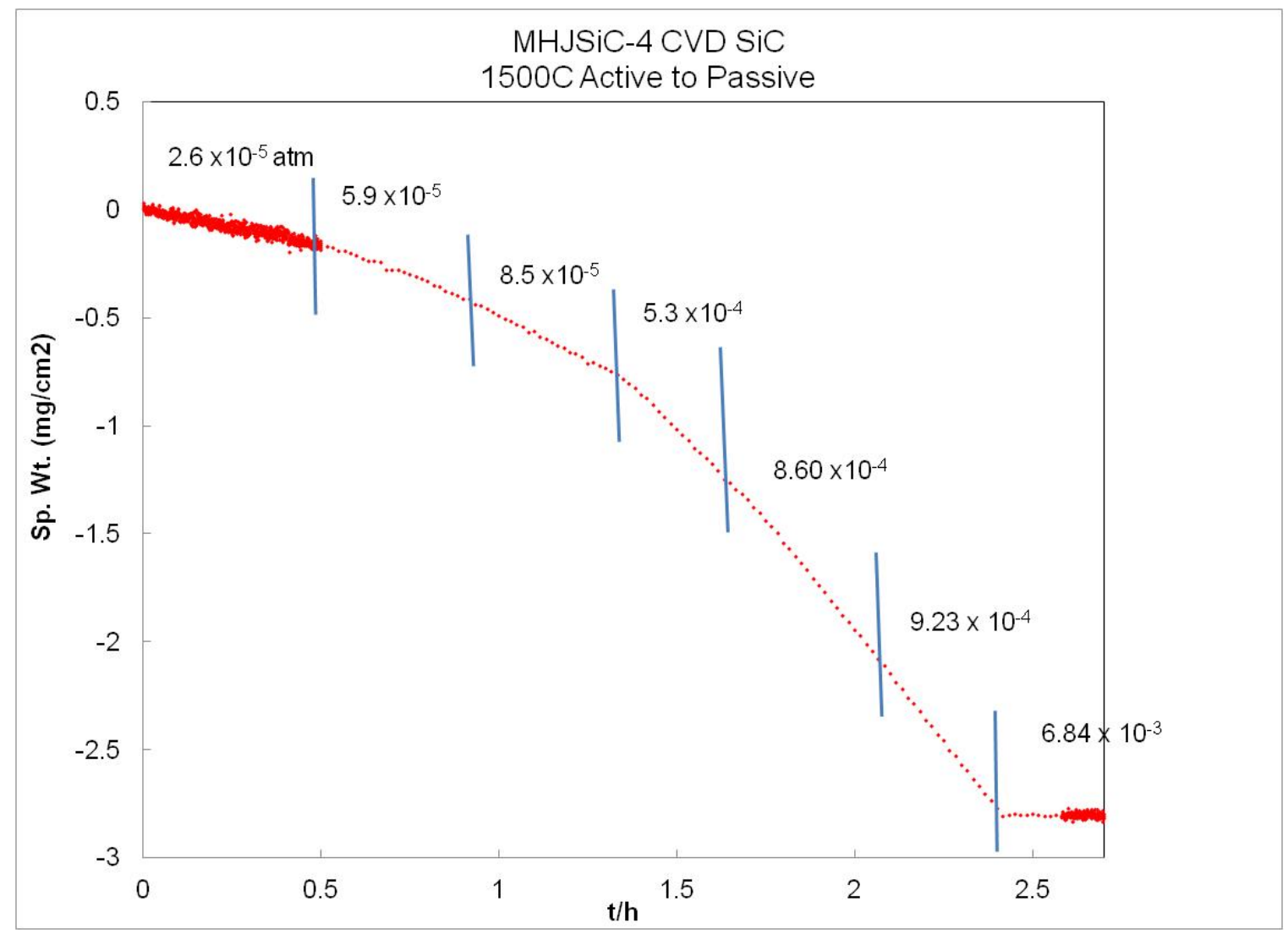

Fig. 5. Passive-to-active transition for stoichiometric $\mathrm{SiC}$ at $1500^{\circ} \mathrm{C}$. 
Extending the condition for scale/substrate equilibrium to that of $\mathrm{SiO}_{2} / \mathrm{SiC}$, the following reactions can be written:

$$
\begin{aligned}
& \mathrm{SiC}(\mathrm{s})+2 \mathrm{SiO}_{2}(\mathrm{~s})=3 \mathrm{SiO}(\mathrm{g})+\mathrm{CO}(\mathrm{g}) \\
& \mathrm{SiC}(\mathrm{s})+\mathrm{SiO}_{2}(\mathrm{~s})=2 \mathrm{SiO}(\mathrm{g})+\mathrm{C}(\mathrm{s}) \\
& 2 \mathrm{SiC}(\mathrm{s})+\mathrm{SiO}_{2}(\mathrm{~s})=2 \mathrm{CO}(\mathrm{g})+3 \mathrm{Si}(\mathrm{s})
\end{aligned}
$$

Analogous with the Wagner condition, Hinze and Graham (3) derived the following expressions for the $\mathrm{P}\left(\mathrm{O}_{2}\right)$ to for the active-to-passive transition:

$$
\begin{aligned}
& P_{\mathrm{O}_{2}}^{A-t o-P}=\left(\frac{D_{C O}}{D_{\mathrm{O}_{2}}}\right)^{1 / 2} P_{C O}^{e q} \\
& P_{\mathrm{O}_{2}}^{A-t o-P}=\left(\frac{D_{S i O}}{D_{\mathrm{O}_{2}}}\right)^{1 / 2} P_{S i O}^{e q}
\end{aligned}
$$

The transition points for different temperatures and for different types of SiC in this study generally cluster about the lines generated from eqns. [6-10], as shown in Fig. 6 . However the correlation between the specific reaction and type of $\mathrm{SiC}$ ( $\mathrm{SiC}$ with excess $\mathrm{Si}$, stoichiometric $\mathrm{SiC}$, or $\mathrm{SiC}$ with excess carbon) is not clear and further studies are needed to understand this.

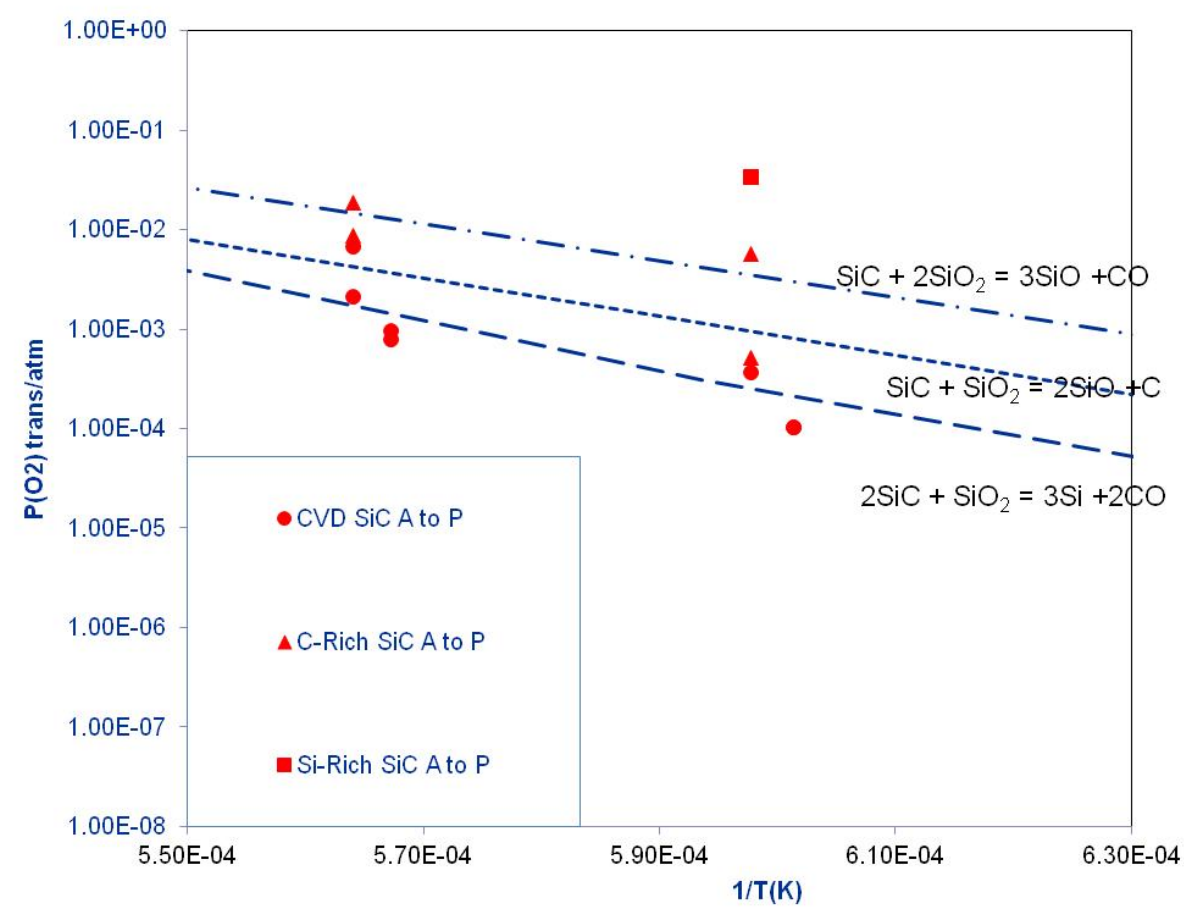

Fig. 6. Measured transition pressures compared to calculated values from scale/substrate equilibrium conditions. 


\section{$\underline{\text { Passive-to-Active Transitions for } \mathrm{SiC}}$}

A series of passive-to-active transitions were measured for the $\mathrm{SiC}$ materials. A representative measurement for stoichiometric $\mathrm{SiC}$ is shown in Fig. 7. The transition from passive-to-active must occur via the breakdown of the ambient passive film. This can occur via several mechanisms:

1. Vaporization of the $\mathrm{SiO}_{2}$ film. This is reaction [5] as discussed by Wagner for $\mathrm{SiO}_{2}$ on Si.

2. Generation of $\mathrm{SiO}(\mathrm{g})$ and $\mathrm{CO}(\mathrm{g})$ at the interface and lifting of the $\mathrm{SiO}_{2}$ film due to gas pressure. This could be one of reactions [6-8].

3. Consumption of the $\mathrm{SiO}_{2}$, due to the interfacial reactions [6-8].

The transition pressures at $1500^{\circ} \mathrm{C}$ are considerably higher than those predicted by reaction [5] at the temperatures of interest, so this mechanism can effectively be ruled out. The micrographs in Figs. 8(a-c) provide some important indications of a probable mechanism for the passive-to-active transition. The breakdown of the passive scale appears to occur with formation of somewhat circular regions of $\mathrm{SiO}_{2}$ loss from the surface, leaving the bare SiC. A close examination of the edges between the regions of $\mathrm{SiO}_{2}$ and $\mathrm{SiC}$ reveals regions where the scale appears to be lifting from the substrate (Fig. 8(b)). This type of behavior is not observed at high oxygen potentials. This lifting is likely caused by gas pressure at the interface, according to mechanism (2) above. Note also that this separating region of scale is somewhat circular, as is the larger region of $\mathrm{SiO}_{2}$ loss. Fig. 8(c) shows thinning of the $\mathrm{SiO}_{2}$ scale at the edge of the exposed $\mathrm{SiC}$. This is likely due to consumption of the $\mathrm{SiO}_{2}$ via the interface reaction (mechanism (3) above). Finally Fig. 8(c) shows rods of $\mathrm{SiO}_{2}$, which are an indicator of $\mathrm{SiO}(\mathrm{g})$ formation and subsequent further oxidation (at higher $\mathrm{P}\left(\mathrm{O}_{2}\right)$ levels) away from the surface. 


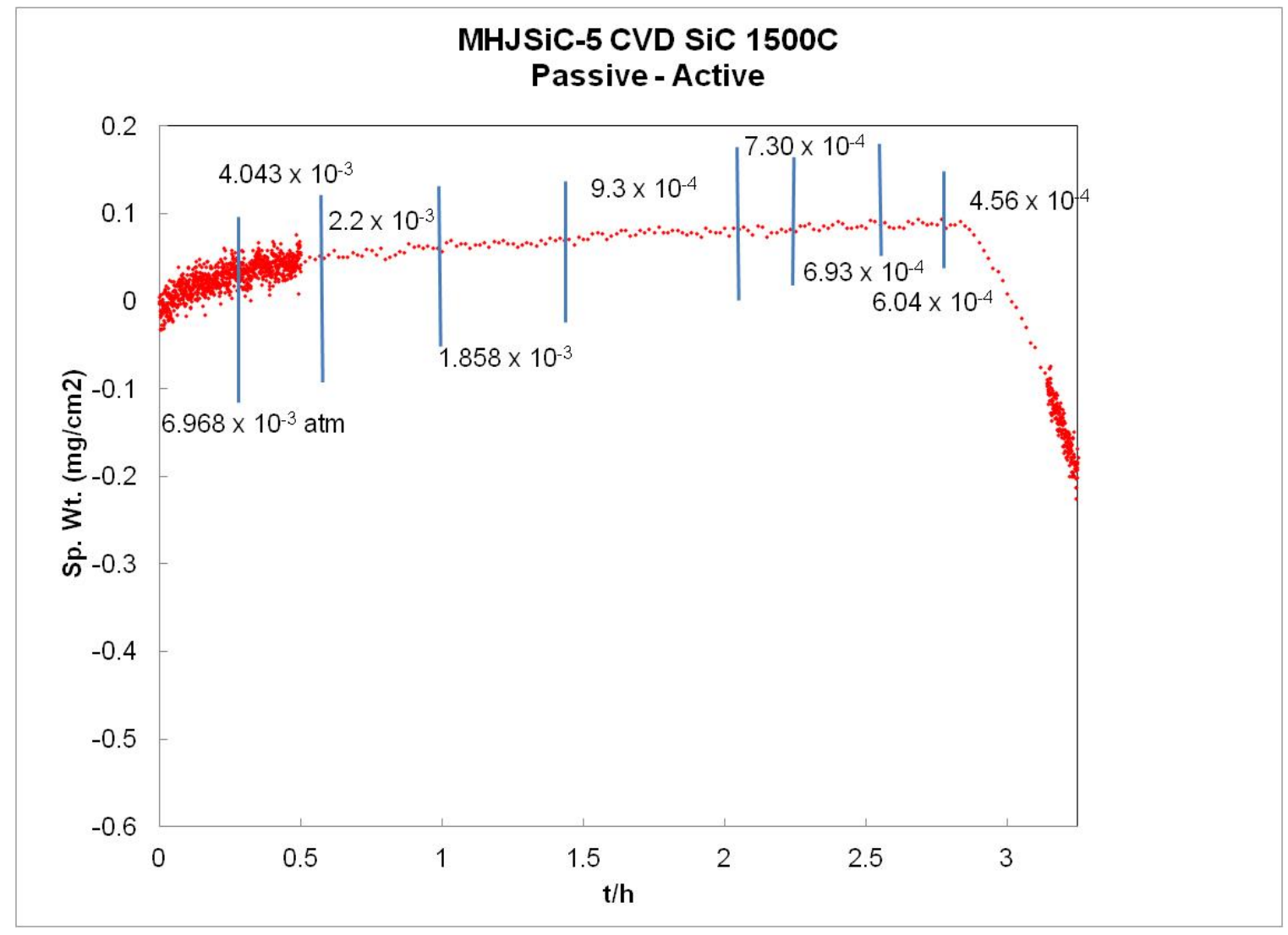

Fig. 7. Passive-to-active transition for SiC.

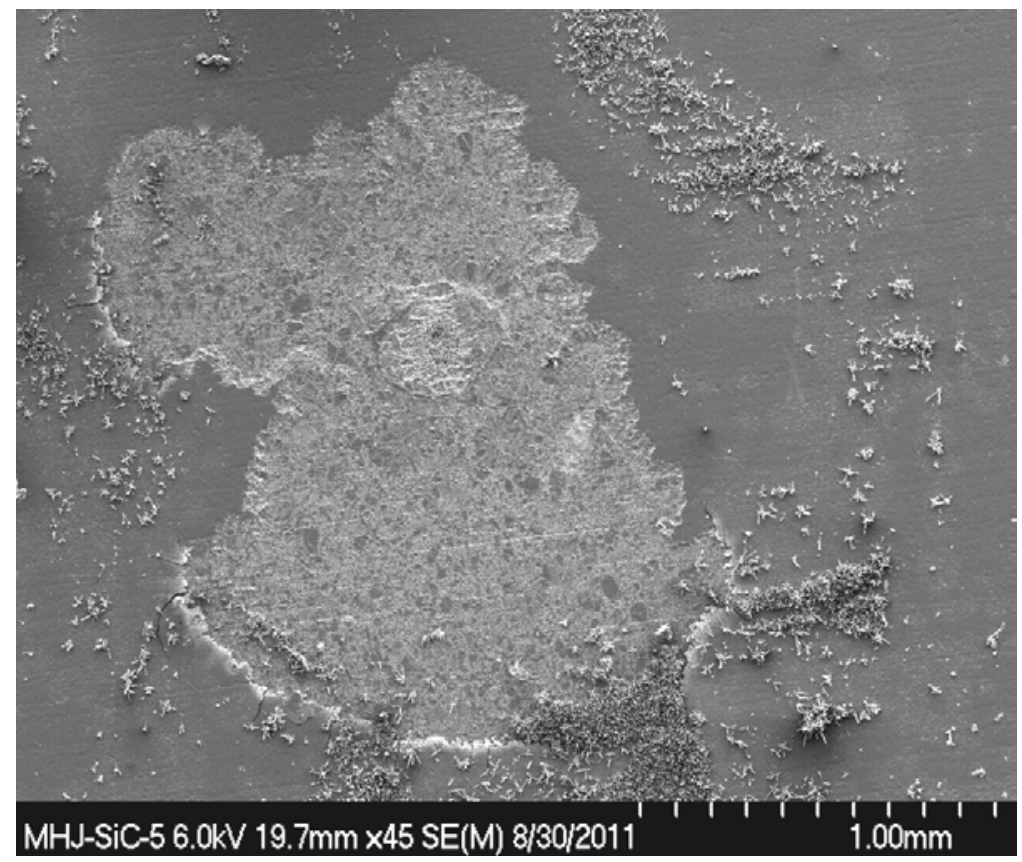

Fig. 8(a) 


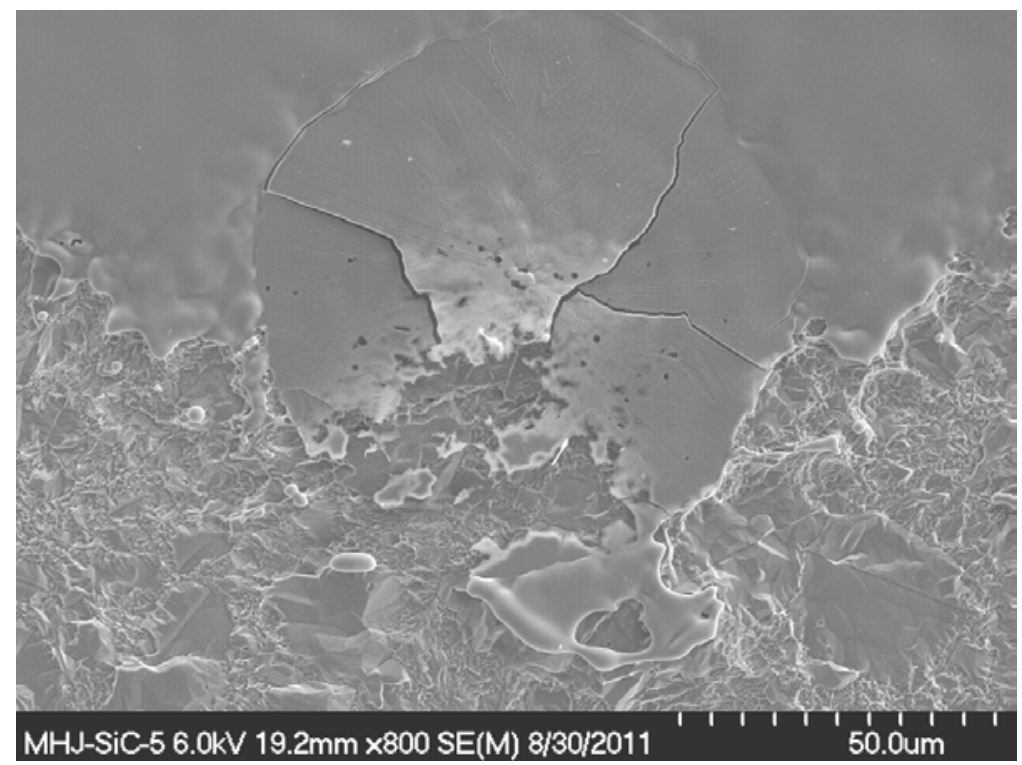

Fig. 8(b)

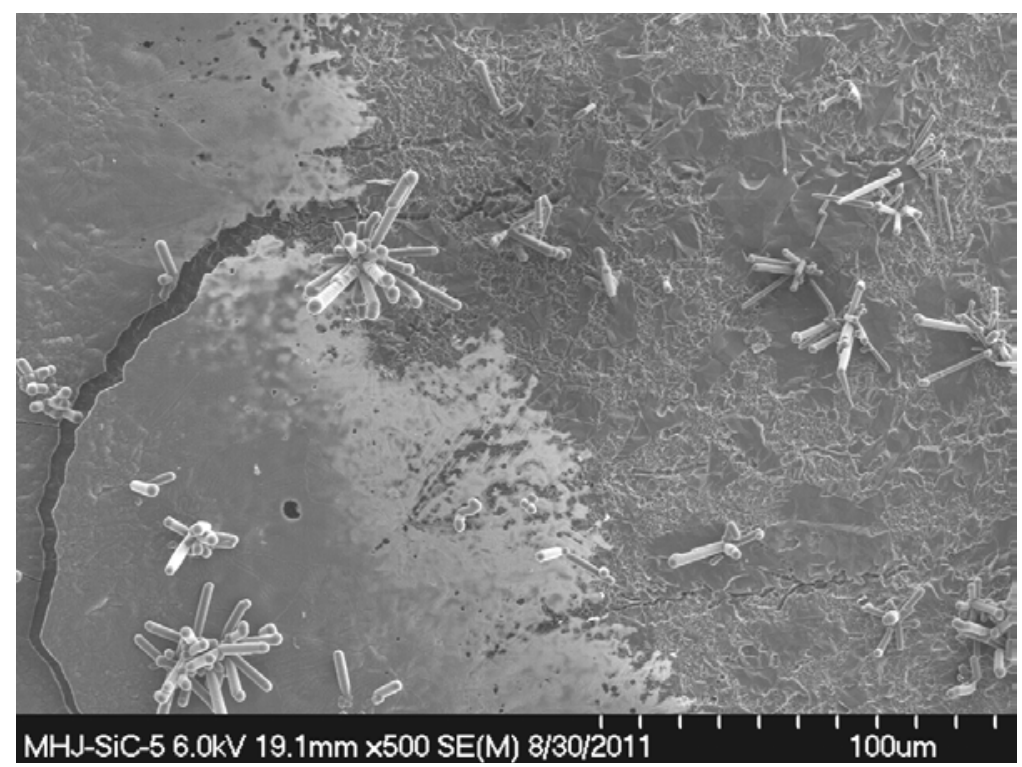

Fig. 8(c).

Fig. 8. SiC sample after passive-to-active transition. (a) Area without a $\mathrm{SiO}_{2}$ film in center. (b) Edge of area without $\mathrm{SiO}_{2}$ indicating lifting of the scale, likely due to interfacial gas generation. (c) Edge of area without $\mathrm{SiO}_{2}$ showing thinning and growth of $\mathrm{SiO}_{2}$ rods, which are an indicator of $\mathrm{SiO}(\mathrm{g})$ formation.

Based on these observations, it is possible to estimate the $\mathrm{P}\left(\mathrm{O}_{2}\right)$ for the passive-toactive transition. As $\mathrm{P}\left(\mathrm{O}_{2}\right)$ is gradually lowered, a point is reached where the interfacial reaction between $\mathrm{SiC}$ and $\mathrm{SiO}_{2}$ is no longer inhibited. Cracks and defects in the $\mathrm{SiO}_{2}$ scale may occur during growth or may occur due to the developing pressure below the scale. $\mathrm{SiO}(\mathrm{g})$ and $\mathrm{CO}(\mathrm{g})$ will escape through these defects, unless there is sufficient $\mathrm{P}\left(\mathrm{O}_{2}\right)$ to react with $\mathrm{SiO}(\mathrm{g})$ and absorb it into the passive scale. This is likely the point at 
which the $\mathrm{P}\left(\mathrm{O}_{2}\right)$ is below the partial pressure of $\mathrm{SiO}(\mathrm{g})$ generated at the $\mathrm{SiC} / \mathrm{SiO}_{2}$ interface, so that the reaction below does not occur:

$$
\mathrm{SiO}(\mathrm{g})+1 / 2 \mathrm{O}_{2}(\mathrm{~g})=\mathrm{SiO}_{2}(\mathrm{~s})
$$

In order to derive this expression we shall use the approach of Turkogan et al. (4). The necessary fluxes for reaction [11] are equated in reaction [12]. The inward flux of $\mathrm{O}_{2}$ is limited by the static boundary layer and described with the mass transfer coefficient, $h . J_{i}$ are the fluxes of species $i, D_{i}$ is the diffusivity of species $i, \delta$ is the thickness of the boundary layer, $R$ is the gas constant, $T$ is the absolute temperature and $P_{i}$ is the partial pressure of species $i$. The maximum flux of $\mathrm{SiO}(\mathrm{g})$, generated by [6] or [7] is given by reaction [13]. In equation [13], $\alpha$ is the vaporization coefficient and $M$ is the molecular weight of SiO. Combining equation [13] with equation [12] results in equation [14], which is the expression for the $\mathrm{P}\left(\mathrm{O}_{2}\right)$ for the passive-to-active transition. Equation [15] is the expression for the mass transport coefficient. Here $v_{\mathrm{O} 2}$ is the viscosity of $\mathrm{O}_{2}, \mathrm{v}_{\mathrm{g}}$ is the gas velocity, and $\mathrm{L}$ is a characteristic length dimension of the sample. The vaporization coefficient used here was determined in earlier measurements by the authors (5). The viscosity was taken from the tables (6).

$$
\begin{aligned}
& J_{S i O}=-\frac{1}{2} J_{O_{2}}=\frac{2 D_{O_{2}}}{\delta R T} P_{O_{2}}=2 h \frac{P_{O_{2}}}{R T} \\
& J_{S i O}^{\max }=\frac{\alpha P_{\text {SiO }}}{\sqrt{2 \pi M R T}} \\
& P_{O_{2}}^{\text {Passive-to-Active }}=\frac{\alpha}{2 h} \sqrt{\frac{R T}{2 \pi M}} \\
& h=0.664\left(\frac{D_{O_{2}}^{4}}{v_{O_{2}}}\right)^{1 / 6}\left(\frac{v_{g}}{L}\right)^{1 / 2}
\end{aligned}
$$

Fig. 9 compares our experimental data to that calculated from eqn. [14]. Agreement is reasonable and much closer to the transition $\mathrm{P}\left(\mathrm{O}_{2}\right)$ calculated from the modified Turkdogan theory than to the $\mathrm{P}\left(\mathrm{O}_{2}\right)$ calculated from the decomposition of the $\mathrm{SiO}_{2}$ scale 


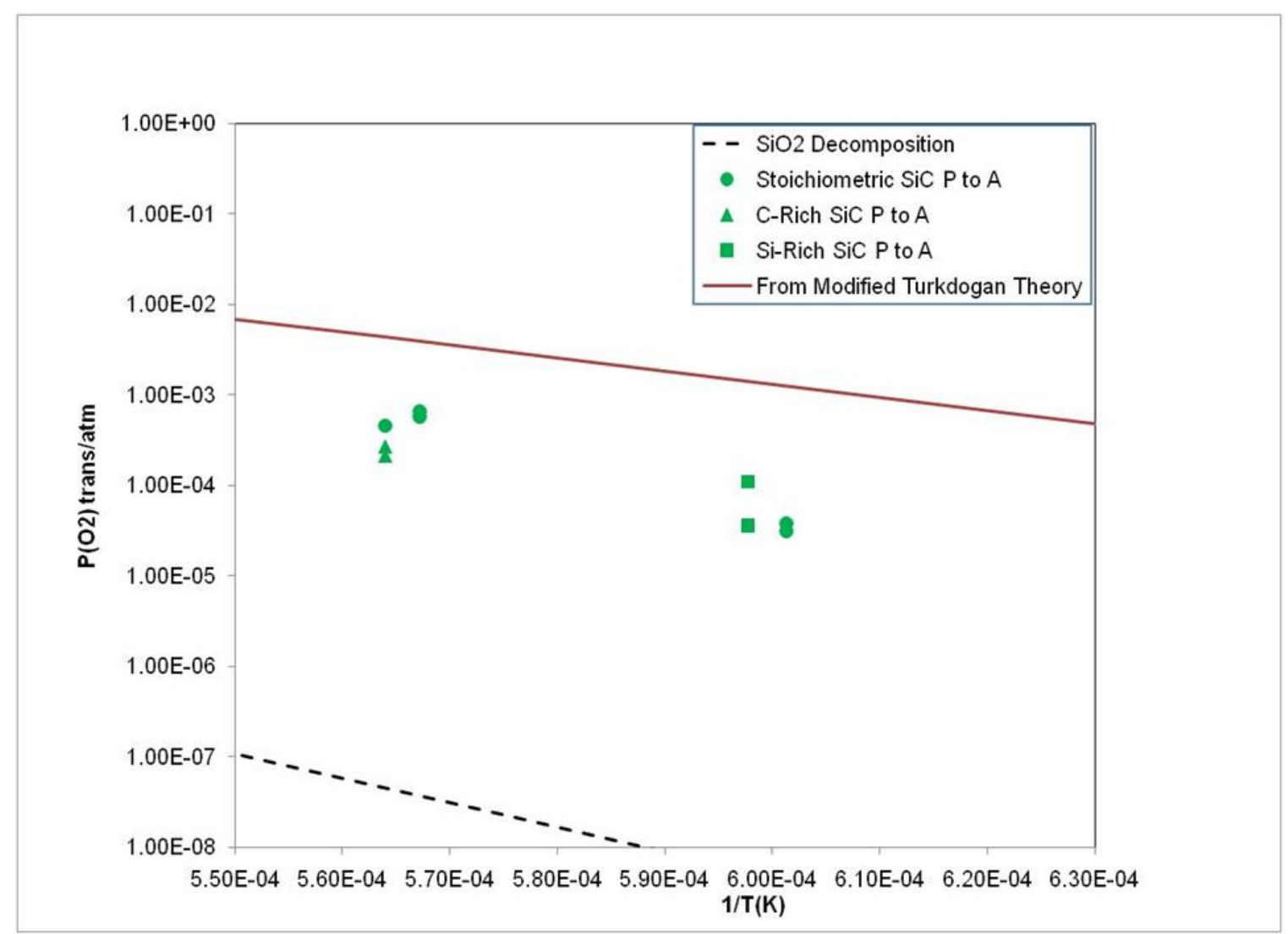

Fig. 9 Comparison of passive-to-active transition points to calculated values of $\mathrm{SiO}_{2}$ decomposition and the modified Turkdogan theory.

\section{Summary and Conclusions}

The hysteresis in the active oxidation of $\mathrm{Si}$ and $\mathrm{SiC}$ has been explored. There is clearly a difference between the active-to-passive and the passive-to-active transition for both $\mathrm{Si}$ and $\mathrm{SiC}$. In the case of $\mathrm{Si}$, our observations are consistent with Wagner's theory. The differences between the $\mathrm{P}\left(\mathrm{O}_{2}\right)$ required for the active-to-passive transition and the passive-to-active transition are less pronounced for $\mathrm{SiC}$ than pure $\mathrm{Si}$. In the case of $\mathrm{SiC}$ the active-to-passive transition is described by the condition for scale/substrate equilibrium. The passive-to-active transition appears to be governed by the interfacial reaction between $\mathrm{SiC}$ and $\mathrm{SiO}_{2}$, which breaks down the $\mathrm{SiO}_{2}$ scale. This mechanism has important applications in understanding the response of SiC-based ceramics and composites to hypersonic re-entry environments.

\section{Acknowledgments}

It is a pleasure to thank Prof. Bob Rapp of The Ohio State University. The idea for this study came from discussions with him. Over the years we have learned much about this and other topics in high temperature oxidation from our discussions and interactions with Bob. 


\section{References}

1. C. Wagner, J. Appl. Phys., 29(9), 1295 (1958).

2. N. Jacobson and D. Myers, Oxid. Met., 75, 1 (2011).

3. J. W. Hinze and H. C. Graham, J. Electrochem. Soc., 123(7), 1066 (1976).

4. E. T. Turkdogan, P. Grieveson, and L. S. Darken, J. Phys. Chem., 67, 1647 (1963).

5. N. S. Jacobson, K. N. Lee, and D. S. Fox, J. Am. Ceram. Soc., 75(6), 1603 (1992).

6. R. A. Svehla, Estimated Viscosities and Thermal Conductivities of Gases at High Temperatures, NASA Technical Report R-132 (1962). 